\title{
A comparative study of cost and quality of life among Skeletal Related Events (SRE) and non-SRE among breast and prostate cancer patients in Malaysia
}

\author{
Noraziani Khamis ${ }^{1 *}$, Sharifa Ezat WP' ${ }^{1}$ Aljunid Syed ${ }^{2}$, Zafar Ahmed ${ }^{1}$ \\ From The 6th International Casemix Conference 2012 (6ICMC2012) \\ Kuala Lumpur, Malaysia. 6-7 June 2012
}

\section{Background}

The human skeleton is the most common organ to be affected by metastatic cancer (skeletal or bone metastases). The prevalence of skeletal disease is greatest in breast and prostate carcinoma. Bone metastases lesions weaken bone structure, causing a range of symptoms and complications. Sufferers of breast and prostate cancers may develop Skeletal related events (SRE). These SRE are defined as pain that require palliative radiotherapy or surgery to bone, hypercalcaemia, pathologic fractures, spinal cord compression and bone marrow failure. These complications contribute to a decline in patients' HRQOL (health related quality of life). However, information on treatment costs of breast and prostate cancers and multidimensional assessments of QOL are limited. Thus this study aim to obtain both cost and QOL of breast and prostate cancers patients and to determine their relationship with the patients sociodemograhic profiles (age, ethnicity, income) and disease profile (tumour types, cancer stages and SRE status).

\section{Objective}

To determine the health care cost and QOL of breast and prostate cancer patients in Malaysia. The association of risk factors (sociodemographic and diseases profiles including SRE status) and cost and QOL will later be determined through statistical analysis.

\footnotetext{
* Correspondence: noraziani17@yahoo.com

${ }^{1}$ National University of Malaysia, Cheras, Kuala Lumpur, Malaysia

Full list of author information is available at the end of the article
}

\section{Methodology}

This will be a societal approach, cost evaluation technique through a cross sectional study for a projected period of 9 months. Both qualitative and quantitative approach to estimate the health care cost of provider and patient's cost through microcosting questionnaire method. Patient's QOL will be using the locally validated EORTC-QLC-C30 questionnaire. Selected patients from oncologic and surgical wards, outpatients specialists clinics will be taken as respondents. Outcomes of study will include cost to treat a case of SRE and projected country's burden of SRE from both cancer. Other outcomes will be compared between SRE and non-SRE through measurements of cost per QALYs; cost per life years saved (LYS) and cost per deaths averted. Associated risk factors will be measured by bivariate and multivariate analyses with power of study of $80 \%$ and $p$ value of 0.05 .

\section{Expected result}

The cost of treatment among prostate and breast cancer patient of lower disease compared to those of higher stages, positive bone metastasis and SRE positive. The QOL will also be expected to be higher among these groups. By similar disease stages for each cancer types, the QOL and costs are expected to be similar.

\section{Conclusion}

This information will provide the cost burden of breast and prostate cancers for the country and will be used for strategic planning for the country. Patients with risk of lower QOL will also be identified for better risk assessment during cancer managements. 


\section{Author details}

${ }^{1}$ National University of Malaysia, Cheras, Kuala Lumpur, Malaysia.

${ }^{2}$ United Nations University International Institute for Global Health, Kuala

Lumpur, Malaysia.

Published: 21 November 2012

doi:10.1186/1472-6963-12-S1-P4

Cite this article as: Khamis et al:: A comparative study of cost and

quality of life among Skeletal Related Events (SRE) and non-SRE among breast and prostate cancer patients in Malaysia. BMC Health Services

Research 2012 12(Suppl 1):P4.

Submit your next manuscript to BioMed Central and take full advantage of:

- Convenient online submission

- Thorough peer review

- No space constraints or color figure charges

- Immediate publication on acceptance

- Inclusion in PubMed, CAS, Scopus and Google Scholar

- Research which is freely available for redistribution

Submit your manuscript at www.biomedcentral.com/submit 